\title{
O Cosmopolitismo pacifista da Bele Époque: uma utopia liberal
}

\author{
Nicolau Sevcenko \\ Departamento de História da FFLCH da Universidade de São Paulo
}

Em um de seus artigos, Antonio Cândido de Mello e Souza lembrou que somente em torno da década de 1930 é que se desenvolveu no país a consciência da nação subdesenvolvida, a idéia do atraso econômico e da marginalização social (1). Seria interessante refletir sobre o porque desse retardamento das avaliações a respeito da verdadeira condição do país no confronto com o chamado mundo desenvolvido. O mesmo autor demonstra a incidência durante praticamente todo o período colonial das fantasias paradisíacas com que os europeus projetavam suas ansiedades e incertezas milenares sobre o Novo Mundo e que já foram matéria de pesquisas minuciosas por estudiosos desse período (2). A essa visão idílica da terra, os românticos brasileiros vieram somar, logo após a Independência, as imagens da natureza luxuriante, do impulso inato à liberdade $\mathrm{e}$ ao heroismo presentes no sangue indígena $\mathrm{e}$ da emotividade exacerbada pela inspiração das belezas naturais. Otimismo liberal e individualista próprio de uma concepção de mundo híbrida da crença mercantilista da prodigalidade da natureza como a fonte da riqueza e do novo culto à plena liberdade de iniciativas, origem le fim de toda harmonia social, segundo a cartilha de Adam Smith.

(1) - Mello e Souza, Antonio Cândido de. "Literatura y Subdesarrollo". In: America Latina en su Literatura. Coord. de Cesar Fernandez Moreno, $4^{\circ}$ edição, Paris, UNESCO, Mexico, Siglo Veinteuno, 1977, pp. 335-337.

(2) - Holanda, Sergio Buarque de. Visão do Paraíso. $2^{\circ}$ ed., São Paulo, Nacional/EDUSP, 1969 e Melo Franco, A. Arinos de. O Indio Brasileiro e a Revolução Francesa. $2{ }^{\circ}$ ed., Rio, José Olympio/Brasília, INL, 1976, principalmente pp. 3-30. 
Ressumbra dessa tradição associada a noção algo eufórica do "pais novo", ou seja, a sua curta existência como país e ainda mais como nação independente, impediu que aflorassem em sua plenitude todas as potencialidades que seu território e seu povo trazem incubadas e latentes em si. Sabemos que essa convicçăo quintessencial ao romantismo perdura até aos últimos estertores desse movimento, ecoando de forma fugaz até períodos muito tardios de nossa história. Mas sabemos igualmente que desde as últimas décadas do séc. XIX, desencadeou-se uma veemente reação contra a escola romântica por todo o país. Diversificada em inúmeras correntes - cientificismo, realismo, naturalismo, parnasianismo, nefelibatismo, verismo e outras mais - esse movimento de resistência se nutre de tal ímpeto graças às intensas transformações históricas operadas tanto no Brasil como no exterior nesse período, que na passagem do século praticamente sufoca os últimos alaridos românticos, impondo-se como senhor absoluto do cenário cultural. Mas o que ele traz como mudança quanto à imagem do país nas representações da sua elite, sobretudo no seu confronto com o Velho Mundo? A resposta a essa inquirição exige um desdobramento do itinerário de nossas reflexões.

As novas correntes cientificistas que avassalaram o mundo da cultura por volta das últimas décadas do séc. XIX e as primeiras do séc. $\mathrm{XX}$, tinham sua origem notoriamente nos grandes desenvolvimentos técnicos e científicos que marcaram a segunda metade do século passado e que induziram os especialistas a denomina-los globalmente de II Revolução Industrial, tal a profundidade e abrangência da sua repercussão. Desponta a partir dessa nova escalada do processo produtivo um mundo novo, dinâmico - em constante e maciço crescimento e expansão - provido de recursos ainda mal explorados, mas cujas potencialidades já se revelavam aparentemente infinitas. Esse panorama recém-descortinado era suficiente entretanto para afugentar em definitivo os fantasmas que tolhiam as iniciativas mais arrojadas da camada empreendedora da burguesia européia. Por muito tempo e particularmente na conjuntura caótica e insegura do primeiro esforço pela implantação da economia industrial, as teorizações a respeito do destino da humanidade sob as novas condições, formuladas pela Economia Política, mais do que desalentadoras, eram apocalípticas.

Michel Foucault, numa análise percuciente, revelou o impasse sob - qual a Economia Política vislumbrava a perspectiva da sociedade diante desse primeiro desencadear de forças produtivas incalculáveis (3). A decorrência teórica mais imediata dos exercícios de análises desta corrente, desde as considerações de Ricardo, fora a introdução da história como recurso de pensamento capaz de acompanhar a mecânica seriada e cu-

(3) - Foucaut, Michel. As Palavras e as Coisas. Lisboa, Portugália, 1967, pp. 331-44. 
mulativa da formação da riqueza através do trabalho. Ora, essa mesma história ao ser desencadeada como método de reflexão, põe em evidência a condição de raridade e escassez que opera simultaneamente como o estímulo e o limite do esforço produtivo do homem. Estímulo porque é somente do trabalho que o homem retira a sua subsistência e limite por que é a escassez e não a abundância que circunsçeve a sua presença no espaço da vida e da natureza. E assim que a Economia Política define a finitude do homem e se torna um saber voltado para o exame da raridade, da carência, da necessidade. Dessa consciência da finitude derivam duas posturas fundamentais. Por um lado Ricardo e Malthus prognosticam uma paralisação do crescimento e da acumulação pelo esgotamento dos recursos naturais, diante do aumento inevitável da população. Por outro, Marx assinalava a caminhada inexorável para a dissolução dessa ordem social em virtude do efeito contraditório pelo qual o processo produtivo reproduz e amplifica criticamente o estado de carência. De qualquer forma, ambas as concepções convergiam para uma situação decisiva final marcada pela ruptura da cadeia histórica e desaguando na própria finitude do tempo.

Por muito tempo, a comunidade dos homens de negócio da Inglaterra procurou demonstrar desprezo e ignorância pelos vacticínios funestos da Economia Política. Mas o estado latente dos seus pavores emergia na legislação conservadora, alerta para as tendências apontadas naqueles textos em tom de profecia (4). A reação mais frequente dentre os empresários comerciais e industriais da burguesia inglesa traduziu-se contudo, numa reversão praticamente unânime a um entendimento diluido e otimizado ao máximo, do mundo econômico concebido por Adam Smith na Riqueza das Nações. O fundamental nessa interpretação repousaria na outorga de uma fé inabalável à eficiência, justiça e imponderabilidade da "mão invisível", que fora a metáfora com que Smith quis significar as regularidades espontâneas do processo de produção e circulação de riquezas. Ficaria dessa forma dissolvido o estorvo representado pela tradição utilitarista da Economia Política, renitente na sua ênfase sobre a necessidade de uma ação controladora e mesmo cerceadora da sociedade sobre o universo econômico, presente de forma indelével no próprio Smith.

Não nos deve surpreender portanto, que tenha sido na França que essa corrente tenha encontrado alguns dos seus mais notáveis teóricos. De fato, fora $\mathrm{em}$ solo francês que se encontraram todas as condições de fertilidade propícias a garantir um pleno desenvolvimento à teoria da Razão Natural, e é certo que Smith auriu alí a inspiração para a sua "mão invisível". Não foi certamente por admirar as suas habilidades clí-

(4) - Robbins, Lionel. Teoria da Politica Econômica. São Paulo, Ibrasa/ EDUSP, 1972, pp. 95-113. 
nicas que Adam Smith quis dedicar a Riqueza das Nações ao Dr. Quesnay (5). Seria pois com a chamada Escola Econômica Francesa, representada em seus nomes por J. B. Say, Frédéric Bastiat e Bastable, que essa atitude a-crítica encontra talvez a sua máxima expressão intelecțual e apologética da economia. Mas sem dúvida quem melhor a executa e dela recolhe os melhores frutos, é a nova burguesia empreendedora inglesa, encabeçada pela liderança impaciente da Câmara de Comércio da Cidade de Manchester. Fato que valeu a atribuição a esse modo de pensar e agir da designação nem sempre lisonjeira de "manchesterismo" ou, impropriamente, de Escola de Manchester (6).

A conjuntura histórica que respaldou o florescimento do manchesterismo na sua plenitude, já se afastava das circunstâncias nebulosas da guerra continental ou das campanhas políticas e econômicas explosivas pelo direito de representação e contra a lei dos cereais, que marcaram impressivamente a elaboração dos últimos estudos da Economia Política. O alívio das tensões internacionais e o longo período de paz secular que se seguiu ao Congresso de Viena, convergem com a assimilação do cartismo e do livre-cambismo à política oficial do govêrno britânico. Em consonância com esses eventos, registra-se um prodigioso período de crescimento econômico, primeiro de 1840 a 1860 , a "era das ferrovias", em que a taxa de exportações da Inglaterra chegou à cifra fantástica de $7,3 \%$ por ano durante toda uma década (1845-55). Expansão que prossegue de 1860 a 1895 de maneira praticamente ininterrupta, mas orientando-se agora, graças principalmente à aplicação dos conhecimento científicos à produção industrial, para a diversificação econômica e a exportação tanto de múltiplos bens de capital, quanto de capital em sí nresmo. Graças a esses processos, a Grã-Bretanha se insurge como a "oficina do mundo" (7). Situação inquestionável e privilegiada, que, entretanto, os manchesterianos pretendiam fosse constante e eterna, evocando a teoria das "vantagens naturais e vantagens adquiridas" de Smith, particularmente ajustável à sua vocação monopolista (8).

Ora, a evolução dessa conjuntura francamente auspiciosa, proporcionou os elementos necessários para a superação presuntivamente definitiva dos argumentos da Economia Clássica e para a plena cristalização do manchesterismo, metamorfoseado em um núcleo autêntico de saber. E mais, como um campo de conhecimentos particularmente decisivo ante

(5) - Heilbroner, R. L. História das Idéias Econômicas. Rio, Zahar, 1964, pp. 36-7.

(6) - Brown, M. B. Economia do Imperialismo. Lisboa, Ulisséia, 1976, pp. 109-112; Hobsbawm, E. A Era do Capital. Rio, Paz e Terra, 1977, p. 311.

(7) - Hobsbawm, E. Industry and Empire. Harmondsworth, Penguin Books, 1975, pp. 109-19 e 134 .

(8) - Teoria que aparece também transfigurada nas "vantagens comparativas" de Ricardo, cf. Brown, op. cit., pp. 102-3. 
os novos horizontes que se abriam, para orientar a conduta e iluminar as expectativas dos homens dos novos tempos. Esse clímax apareceria, em seu aspecto mais bem acabado, na síntese operada por $H$. Spencer, filósofo por excelência do séc. XIX, pelo menos no que concerne à divulgação. Seu sistema é bastante simples, apesar do ecletismo vistoso que ostenta, e sua eficácia para traduzir o estado de espírito e a visão de mundo da burguesia vitoriana inglesa é nada menos do que notável.

A idéia básica estruturadora do seu pensamento é a de progresso. Bem se vê aí, uma solução para o impasse da Economia Clássica: nem a paralisação corrosiva do mundo de Ricardo, nem a catástrofe de Malthus, nem a turbulência peremptória dos textos de Marx; mas a mudança suave e de sentido previamente determinado, sempre para mais, para melhor e para mais distante. E fácil verificar aí a manifestação de duas das idéias mais caras da tradição utilitarista do pensamento inglês: o aperfeiçoamento cumulativo e a felicidade material dos homens como os objetivos maiores de toda ação que se pretenda digna. Visível também é uma compreensão simplista e deformada da teoria da evolução biológica das espécies, que graças à amplitude da repercussão que causou no período, poderia equivaler a uma confirmação da tendência imanente da natureza ao progresso, entendido como evolução integradora, morosa, aprimoradora, cumulativa e infinita. E igualmente notável por fim, a propensão positivista para o estabelecimento desse progresso como uma Lei Geral, característica da ordem natural e social e portanto inexorável. Como tal, ela só poderia ser vislumbrada e adequadamente compreendida pela Ciência, para que a ação dos homens se deixasse modelar complacentemente pela ordem natural do cosmos e suas energias criativas intrínsecas, de modo a não comprometer as harmonias físicas e a disposição social inata para a felicidade.

A contrapartida dessa atitude de espírito na área estritamente econômica, manifesta-se através da corrente de pensamento conhecida como Escola Marginalista e que dominou os últimos decênios do séc. XIX. Conduzida pelos estudiosos dessa vertente, a pesquisa sofre uma transformação cabal no seu estilo, métodos, problemas e enunciados. A noção das regularidades imanentes do mercado é reforçada e se reflete nas formalizações abstratas sobre a concorrência perfeita; a ênfase nas problemáticas transfere-se da esfera da produção para a do consumo; são abandonados os últimos resquícios do enfoque histórico introduzido por Ricardo $\mathrm{e} a$ análise se circunscreve às projeções abstratas dos modelos. Tanto as exposições como as conclusões passam a ser expressas em linguagem matemática e a sucessão das equações por sua vez, esforça-se para demonstrar uma tendência para o crescimento permanente. Eis aí a idéia do progresso evidente como o resultado da adoção de uma análise a-histórica, fundada num raciocínio formalista e plasmada numa linguagem anódina. Para completar essa metamorfose na linha do evolucionismo de 
Spencer, a economia marginalista passa à se arrogar foros de ciência positiva, encarregada de metodizar e quantificar o moto-perpétuo da acumulação, entendido como a própria contabilidade do prazer crescente dos homens, como no Felicific Calculus de F. Y. Edgeworth (9).

Tanto entusiasmo e um otimismo panglossiano não poderiam se sustentar sem alicerces. De fato, a prodigiosa expansão européia da segunda metade do séc. XIX envolve praticamente todas as áreas do globo terrestre numa teia única e estreita de relações e intertesses, timbrada pela circulação de homens, mercadorias e informações num volume e num ritmo tais que somente a Revolução Tecnológica desse período, aplicada a diferentes meios de transporte e comunicação pode explicar. As condições eram tão favoráveis ao pleno desenvolvimento dos negócios europeus, que justificam sobejamente a figura do "Eldorado" ou da "República da Utopia" com que Keynes as quis enquadrar. Maurice Crouzet as descreve como "a imagem de um mundo próspero, franqueado, onde as barreiras de todas as espécies acham-se reduzidas ao mínimo, onde os homens, mercadorias, capitais e idéias circulam livremente, onde a produção e o comércio da Europa atingem o mais alto nível até então alcançado na história da humanidade" (10). Assistia-se à maré montante do cosmopolitismo e do progresso, conceitos praticamente sinônimos a essa altura, o estado eufórico das esperanças media-se pelo ritmo frenético das bolsas de valores. Não foi por acaso que os franceses atribuiram a esse período o epíteto gracioso de Belle Epoque.

Mas em torno da década de 1890 , as primeiras rachaduras aparecidas no edifício liberal desde a Grande Depressão, começam a abalar os seus alicerces mais profundos. A expansão da Revolução Industrial para o continente desde meados do séc. XIX desencadeara os primeiros atritos de concorrência entre as potências económicas. Os efeitos da Depressão incentivaram processos de cartelização, trustização e crescimento da intervenção estatal no seu interior, acirrando as rivalidades. A corrida expansionista e as primeiras leis protencionistas marcam um fim mais do que um começo. A economia acadêmica francesa, instigada por Jules Ferry, abandona o livre-cambismo incondicional dos seus fundadores; a escola histórica alemã fornece todos os subsídios para a legitimação da política alfandegária do Reich; Francesco Crispi reproduzia no Reino da Itália a legislação xenófoba da União Pàn-Germânica. Na própria Inglaterra, a ação conjunta de $\mathbf{J}$. Chamberlain e Cecil Rodhes forneceu as bases para a guinada neo-mercantilista da última fortaleza livre-cambista (11).

(9) - Heilbroner, op. cit., pp. 154-55; Lekachman, R. História das Idéias Econômicas. Rio, Bloch, 1973, pp. 236-68.

(10) - Crouzet, M. A Epoca Contemporânea. Col. História Geral das Civilizaçōes. $4^{\text {a }}$ edição, tomo VII, vol. 15, São Paulo, Difel, 1977, p. 9.

(11) - Mommsen, W. La Epoca del Imperialismo. $2^{\circ}$ ed., Madrid, Siglo Veinteuno, 1973, pp. 5-34. 
Eram já os prenúncios do período da Paz Armada. Um militante doutrinário do liberalismo inglês como Bruce Smith, reconhecia com amargura no fim do século que "a função agressiva do liberalismo havia se esgotado" (12). Uma tentativa de "renovação do liberalismo" se articula por volta de 1895 em torno da Escola de Londres, reunindo nomes expressivos como os de Hobson, Hobhouse, Spencer, Courthey e Brailsford, mas admitindo já a superação das formulações simplistas do laissez-faire e disposto a um amplo programa de reformas econômicas, políticas e sociais. E mesmo assim permanecem como uma corrente minoritária e de pouca expressão na Inglaterra (13). Já ninguém mais no palco europeu admitia as prerrogativas da Inglaterra como a "oficina do mundo". O engodo teórico das "vantagens naturais" fora desmontado por Rodbertus e List, o cosmopolitismo despido na sua crueza imperialista por Hobson e Hilferding. Os efeitos negativos e destrutivos do progresso começam a ser debatidos e divulgados pelos fabianos. A irrupção da Grande Guerra viria referendar as opiniões desses dissidentes e estabelecer o declínio definitivo do milênio liberal do séc. XIX.

A adoção das economias obsidionais durante o conflito, a rearticulação da produção em virtude dos fornecimentos de guerra e o bloqueio de submarinos, interrompem o fluxo internacional das mercadorias, forçando o mercado mundial a readaptações drásticas. A intensidade e duração imprevistas do confronto militar contribuiram para acentuar os processos de composição orgânica e concentração do capital industrial, além de exigirem uma interferência direta ou indireta dos Estados nas condições gerais do mercado e em proveito de grupos particulares de empresas (14). A ruptura teórica com o sonho manchesteriano não se fez demorar. Quatro anos após o Tratado de Versalhes, em 1922, J. H. Clapham lançava as primeiras dúvidas sobre as bases da eccnomia marginalista. Em 1926 o italiano Piero Sraffa, então em Cambridge, iniciava a demolição do idílio conceitual da concorrência perfeita. Os suecos Erik Lindhal e Gunnar Myrdal, nos fins da década de 1920, o polonês Michal Kalecki e Joan Robinson em 1933, autora da Economia da Competição Imperfeita, vieram acelerar esse processo demolitório. Mas coube a John Maynard Keynes, com sua Teoria Geral do Emprego, do Juro e da Moeda, de 1936, o papel de reconstruir sobre os escombros do marginalismo um novo edifício teórico,

(12) - Smitih, Bruce. Liberty and Liberalism. Apud Mommsen, op cit., p. 7.

(13) - Gollwitzer, Heinz. O Imperialismo Europeu. Lisboa, Verbo, s/d.,p. 128; Mommsen, op. cit.

(14) - Allen, G. C. "The Economic Map of The World: population, commerce and industries." In: The New Cambridge Modern History. Cambridge, University Press, 1960, pp. 16-7; Sweezy, P. M. Teoria do Desenvolvimento Capitalista. $3^{\circ} \mathrm{ed}$., Rio, Zahar, 1973; pp. 348-51; Crouzet, M. op. cit., pp. 24-7; Jouvenel, B. de. As Origens do Estado Moderno. Rio Zahar, 1978, pp. 278-98. 
reatado com a tradição da Escola Clássica e sua ênfase sobre a escassez, muito embora numa versão agora mais otimizada (14).

A conciência do subdesenvolvimento só pode nascer quando morre a crença de que os parceiros econômicos estão em condições iguais sempre que efetuam uma troca. E na década de 1930 não era preciso ler as obras de Joan Robinson ou J. M. Keynes para poder compreender esse fato. O espetáculo pungente da Crise fornecia um quadro panorâmico da falência do modelo liberal propagandeado pelos comerciantes de Manchester e pelos professores de Londres, em todas as suas variações cromáticas. O resultado dessa debacle irremediável das instituições da economia livre-concorrencial, foi a adoção de formas políticas centralistas marcadas por um empenho obstinado de planejamento econômico e controle social. Suas feições podiam variar da Frente Popular francesa, ao New Deal americano, ou às soluções autoritárias tão tristemente célebres da Itália e da Alemanha (16). $O$ desdobramento desses processos ao nível da história do Brasil tornam-se por demais evidentes através do Golpe de 1930 e principalmente da imposição do Estado Novo em 1937.

Retomando agora a nossa argumentação inicial, não fica tão difícil entender a incorporação tardia da noção de subdesenvolvimento à consciência cultural e política das elites brasileiras. Assim como na Europa, Japão e EUA, o Brasil que desde a grande expansão da economia cafeeira em fins do séc. XIX, passara a compartilhar da divisão internacional da produção beneficiando-se satisfatoriamente das suas "vantagens naturais", nutriu-se com vivo interesse das concepções do cosmopolitismo pacifista. As suas principais metrópoles comerciais - Rio de Janeiro e São Paulo - foram inclusive alvo de um processo de transfiguração física, adotando as feições urbanas de suas pretensas congêneres às margens do Tâmisa e do Sena. Os personagens que circulavam no seio desses dois novos centros internacionais, revestidos de fachadas art-nouvéau, trajavam-se segundo o melhor figurino do dandy e do bel-ami e, durante o período da Guerra, cumprimentavam-se ao se cruzarem tocando na aba das cartolas e saudando-se com um breve porém enfático "Vive la France!" (17).

Com o advento da nova ordem republicana em 1889 , o país, após um breve período de turbulência, cairia sob a hegemonia da elite paulista já em

(15) - Lekachman, R. op. cit., pp. 374-5; Shakle, G. L. S. Um Esquema de Teoria Econômica. Rio, Zahar, 1969, pp. 60-1; Robinson, J. Liberdade e Necessidade. Rio, Zahar, 1971, p. 76; Horowitz, D. (org.) A Economia Moderna e o Marxismo. Rio, Zahar, 1972, pp. 12 e 145.

(16) - Crouzet, M. op. cit., pp. 147-59.

(17) - Sevcenko, N. Euclides da Cunha e Lima Barreto: a literatura como missão, 1900-1920. Tese de Doutoramento defendida na FFLCH da USP em 1981, mimeo., pp. 2-24 (sob a orientação da Profa. Maria Odila Leite da Silva Dias).

(18) - Idem, pp. 27-38. 
1894, com a ascensão de Prudente de Morais. Hegemonia sob a qual se manteria até a irrupção do movimento de 1930. Essa elite paulista se encarregaria de articular os interesses da cafeicultura com as do crédito internacional, indispensável à sua manutenção e expansão, reforçando a idéia da vocação inata do país para a agricultura de exportação em larga escala, a qual se equilibraria com a importação dos manufaturados e dos capitais europeus numa relação de harmonia e perfeita interdependência (18). Essa se tornou a fé dos dirigentes republicanos e de uma forma geral, de toda a burguesia que se beneficiava do modelo internacionalizado da economia brasileira. Era essa a razão porque um veículo conservador como o Jornal do Comercio do Rio de Janeiro publicava com destaque as idéias de um conferencista de grande sucesso que afirmava, com um agudo sentido das expecta_ tivas do seu público, "que a Humanidade quando chegar ao estado mais lúcido de sí mesma, será como um cristal, com as suas faces definidas e que essas faces serão as pátrias - como expressões práticas da função trabalhadora das nacionalidades" (19).

Um imenso cristal, com faces bem definidas: eis uma metáfora que exprime com um brilho ímpar a utopia do cosmopolitismo pacifista e/ou progressista. Sabe-se que o objetivo de um bom trabalho de lapidação é obter faces o mais perfeitamente possível simétricas e idênticas entre sí que fôr possível. E se as faces são as pátrias, elas aparecerão por fim primorosamente equiparadas e indissoluvelmente ligadas numa imensa obra-prima, que é também um símbolo de riqueza,gosto elevado e consumo conspícuo. Versões igualmente metafóricas, embora bem mais dinâmicas dessa mesma idéia, seriam o organicismo spenceriano e a solidariedade comteana, ambas ressaltando o efeito vital da interdependência entre os vários componentes do organismo social e das várias sociedades entre sí. Aliás, a dupla Comte-Spencer constituia o próprio âmago da formação das Academias de Direito do país, particularmente a de São Paulo, de onde saiu o núcleo dirigente da elite republicana (20).

Essa crença se constituiria pois como que numa consciência-limite no contexto da Primeira República, uma vez que a manutenção de todo o siste_ ma econômico implantado dependia da fé inabalável nesse conjunto de conviç̧ões. $\mathrm{E}$ mesmo os intelectuais que formularam as críticas mais contundentes contra as estruturas de sustentação do regime do primeiro período republicano - como Euclides da Cunha e Lima Barreto -, apontando-lhe a instabilidade intrínseca, bem como o alto grau de marginalização social e irracionalidade econômica, atuaram circunscritos a esse horizonte intelectual mais amplo. Tomemos por exemplo um depoimento de Lima Barreto sobre o melhor destino reservado à humanidade: "Por que o fim da civilização não é a guerra, é a paz, é a concórdia entre os homens de diferentes

(19) - Jornal do Comercio, 03/09/1916, Rio de Janeiro.

(20) - Sevcenko, N. op. cit., pp. 29-37. 
raças e de diferentes partes do planeta; é o aproveitamento das aptidões de cada raça e de cada povo para o fim último do bem-estar de todos os homens" (21). Impossível imaginar uma declaração de fé mais expressiva do cosmopolitismo pacifista. Eis emersa novamente a teoria do grande cristal multifacetado.

Enquanto fosse esse o parâmetro para a compreensãó das relações intersocietárias, é fácil perceber-se, seria difícil aflorar uma consciência aguda das diferenças estruturais existentes entre as nações européias, o Japão e os EUA e as demais sociedades do globo. Muito mais difícil ainda, seria apontarem-se alternativas que extrapolassem essa situação, uma vez que ela própria não era compreendida por inteiro. Assim, mesmo um nacionalista radical como Alberto Torres, que desde 1915 denunciava os efeitos nefastos da influência do "imperialismo" europeu e norte-americano sobre o Brasil, jamais conseguiria romper esse círculo de ferro da consciência ideológica que marcou o seu tempo (22). O espírito nacionalista, parcialmente crítico, parcialmente ufanista, que se seguiu à Primeira Guerra e que no Brasil serviu de inspiração para o Movimento Modernista de 22, já traria os primeiros fermentos da crítica do cosmopolitismo pacifista. Mas seria somente a crise da economia liberal em 1929, tanto no mundo como no Brasil, que viria abrir espaço para a irrupção de novas formas de consciência cultural e política. Querer encontrá-las ou pretender cobrá-las aos escritores e agentes históricos antes desse tempo, é acreditar que se possa colher o fruto antes da flor.

(21) - Lima Barreto. Bagatelas. São Paulo, Brasiliense, 1956, p. 249. Euclides da Cunha depõe no mesmo sentido em Obra Completa, Rio, Aguilar, 1966, vol. I, pp. 604-5.

(22) - Marson, Adalberto. A Ideologia Nacionalista em Alberto Torres. São Paulo, Duas Cidades, 1979, pp. 81-97, principalmente pp. 95-7. 